\title{
HUBUNGAN ANTARA DUKUNGAN KELUARGA DENGAN TINGKAT KECEMASAN PASIEN PRE OPERASI DI RSUD ANDI MAKKASAU KOTA PAREPARE
}

\section{Relationship Between Family Support with Anxienty Level of Anxiety Pre-Operation Patients in Andi Makkasau Hospital, Parepare City}

\author{
Nofriani Mangera, Haniarti, Ayu Dwi Putri Rusman \\ (Program Studi Kesehatan Masyarakat Fakultas Ilmu Kesehatan Universitas Muhammadiyah \\ Parepare) \\ (nofrianimangera100@gmail.com, 082346577442)
}

\begin{abstract}
ABSTRAK
Dukungan keluarga adalah sikap, tindakan dan penerimaan keluarga terhadap penderita yang sakit. Anggota keluarga memandang bahwa orang yang bersifat mendukung selalu siap memberikan pertolongan dan bantuan jika diperlukan. Kecemasan merupakan bagian dari kehidupan manusia yang ditandai dengan perasaan ketakutan atau kekhawatiran yang mendalam dan berkelanjutan. Berdasarkan data awal yang diperoleh dari Rumah Sakit Umum (RSUD) Andi Makkasau Kota Parepare pada tahun 2016 tercatat sekitar 1.254 pasien pre operasi dan pada bulan Mei 2017 tercatat sekitar 112 pasien pre operasi di Rumah Sakit Umum Andi Makkasau Kota Parepare. Penelitian ini bertujuan untuk mengetahui hubungan antara dukungan keluarga inti, dukungan keluarga di luar rumah, dan dukungan keluarga lain dengan tingkat kecemasan pasien pre operasi di Rumah Sakit Umum RSUD Andi Makkasau Kota Parepare. Jenis penelitian ini bersifat deskriptif dengan menggunakan pendekatan cross seetional yaitu pengumpulan data yang menggunakan kuesioner dengan jumlah sampel 112 responden. Teknik pengambilan sampel dalam penelitian ini menggunakan teknik accidental sampling. Sampel yang digunakan sebanyak 53 orang. Analisis data dengan menggunakan teknik Analisis Univarisat dan Analisis Bivariat. (uji statistik chi-square). Hasil penelitian, menunjukkan ada hubungan antara dukungan keluarga inti dengan tingkat kecemasan pasien pre operasi dengan nilai $(\rho=0,00)$ di Rumah Sakit Umum (RSUD) Andi Makkasau Kota Parepare. Disarankan kepada keluarga pasien untuk memberikan dukungan dan rasa nyaman kepada pasien sehingga pasien tidak cemas sebelum operasi, bagi tenaga kesehatan untuk lebih ditingkatkan dalam membantu keluarga pasien untuk menjalankan fungsinya dalam memberi dukungan agar tingkat kecemasan pasien pre operasi menjadi berkurang dan kepada keluarga pasien agar selalu mendampingi pasien dan memberikan motivasi yang baik sehingga pasien tidak cemas sebelum operasi.
\end{abstract}

Kata kunci: Dukungan keluarga, tingkat kecemasan pasien pre operasi

\section{ABSTRACT}

Family support is the attitude, actions and family acceptance of patients who are sick. Family members see that people who are supportive are always ready to provide help and assistance if needed. Anxiety is a part of human life that is characterized by feelings of fear or anxiety that are deep and ongoing. Based on preliminary data obtained from the General Hospital (RSUD) Andi Makkasau in Parepare City in 2016 there were approximately 1,254 preoperative patients and in 
May 2017 there were 112 preoperative patients at the Andi Makkasau Parepare City General Hospital. This study aims to determine the relationship between nuclear family support, family support outside the home, and other family support with the level of anxiety of preoperative patients at the General Hospital of Andi Makkasau Hospital, Parepare City. This type of research is descriptive by using a cross-sectional approach that is collecting data using a questionnaire with a sample of 112 respondents. The sampling technique in this study uses accidental sampling technique. The sample used was 53 people. Data analysis using Univariate Analysis and Bivariate Analysis techniques. (chi-square statistical test). The results of the study showed that there was a relationship between nuclear family support and the level of preoperative patient anxiety and the value $(\rho=0.00)$ at the Andi Makkasau General Hospital (RSUD) in Parepare City. It is recommended to the patient's family to provide support and comfort to the patient so that the patient is not anxious before the operation, for health workers to be further improved in helping the patient's family to carry out its function in providing support so that the level of anxiety of the preoperative patient is reduced and to the patient's family to always accompany patient and provide good motivation so that patients are not anxious before surgery.

Keywords: family support, preoperative patient anxiety level 


\section{PENDAHULUAN}

Tindakan operasi berhubungan dengan resiko yang perlu dibicarakan dengan pasien dan keluarga tentang resiko pre operasi. Pengambilan keputusan operasi dan kepentingannya harus dihubungkan dengan manfaat terapi yang mungkin diperoleh terhadap resiko operasi. Persiapan sebelum operasi sangat penting dilakukan untuk mendukung kesuksesan tindakan operasi. Persiapan operasi yang dapat dilakukan diantaranya persiapan fisiologis merupakan persiapan yang dilakukan mulai dari persiapan fisik, persiapan penunjang, pemeriksaan status anastesi sampai informed consent. Selain itu persiapan mental atau psikologis, persiapan mental merupakan hal yang tidak kalah pentingnya dalam proses persiapan operasi karena mental pasien yang tidak siap atau labil dapat berpengaruh terhadap kondisi fisiknya. Persiapan mental dapat dilakukan dengan bantuan keluarga atau perawat.

Dukungan keluarga adalah suatu proses hubungan antara keluarga dan lingkungan sosialnya. ${ }^{1}$ Dukungan keluarga adalah proses yang terjadi sepanjang hidup, dimana sumber dan jenis dukungan keluarga berpengaruh terhadap tahap lingkaran kehidupan keluarga. Ada tiga dimensi interaksi dalam dukungan keluarga yaitu timbal balik (kebiasaan dan frekuensi hubungan timbal balik), nasihat/umpan balik (kuantitas/kualitas komunikasi) dan keterlibatan emosional (meningkatkan intimasi dan kepercayaan) di dalam hubungan sosial. ${ }^{2}$

Sebelum dilakukan operasi terdapat masalah kecemasan yang merupakan reaksi emosional pasien yang sering muncul. Kecemasan pada pasien pre operatif dapat disebabkan takut terhadap nyeri atau kematian, takut tentang deformitas atau ancaman lain terhadap citra tubuh. Selain itu pasien juga sering mengalami kecemasan lain seperti masalah finansial, tanggung jawab terhadap keluarga dan kewajiban pekerjaan atau ketakutan akan prognosa yang buruk dan probabilitas kecacatan di masa datang. ${ }^{3}$

Kecemasan pada pasien pre operasi harus diatasi karena dapat menimbulkan perubahan-perubahan fisiologis yang akan menghambat, dilakukannya tindakan operasi. ${ }^{4}$ Kecemasan berfungsi sebagai barometer untuk mengukur tingkat dukungan sosial. Jika kontak sosial hilang, perasaan terasing yang menyakitkan, seperti kesepian dan ketidakberdayaan, memotivasi upaya untuk membangun kembali kontak dan kepedulian. ${ }^{5}$

Klien yang tingkat kecemasannya tinggi tidak akan mampu berkonsentrasi dan memahami kejadian selama perawatan dan prosedur. Dalam hal ini dibutuhkan dukungan keluarga dengan mengingatkan informasi dan pengarahan yang telah diberikan oleh perawat. ${ }^{6}$

Berdasarkan data dari World Health Organization (WHO) pada tahun 2013 
menganalisis data dari 35.539 pasien pre operasi dirawat di unit perawatan intensif antara 1 Oktober 2010 dan 30 September 2013. Dari 8.992 pasien $(25,1 \%)$ mengalami kondisi kejiwaan dan 2.473 pasien (7\%) mengalami kecemasan.

Data awal yang diperoleh dari Rumah Sakit Umum (RSUD) Andi Makkasau Kota Parepare pada tahun 2016 tercatat sekitar 1.254 pasien pre operasi dan pada bulan Mei 2017 tercatat sekitar 112 pasien pre operasi di Rumah Sakit Umum Andi Makkasau Kota Parepare.

Sebagian besar pasien beranggapan bahwa operasi merupakan pengalaman yang menakutkan. Reaksi cemas ini akan berlanjut bila pasien tidak pernah atau kurang mendapat dukungan keluarga dan kurang mendapat informasi yang berhubungan dengan penyakit dan tindakan yang dilakukan terhadap dirinya. Setiap pasien pernah mengalami periode cemas, apalagi pasien yang akan menjalani tindakan operasi. $^{7}$

Ketakutan dan kecemasan yang dirasakan pasien pre operasi ditandai dengan adanya perubahan-perubahan fisik seperti meningkatnya frekuensi nadi dan pernafasan, gerakan-gerakan seperti telapak tangan yang lembab, gelisah, menanyakan pertanyaan yang sama berulang kali, sulit tidur, dan sering berkemih, untuk itu diperlukan kerjasama yang baik antara masing-masing komponen yang berkompeten untuk menghasilkan operasi yang optimal. ${ }^{8}$
Berdasarkan uraian tersebut penulis tertarik untuk melakukan suatu penelitian dengan judul "Hubungan antara Dukungan Keluarga dengan Tingkat Kecemasan Pasien Pre Operasi di Rumah Sakit Umum (RSUD) Andi Makkasau Kota Parepare”.

\section{METODE PENELITIAN}

Jenis penelitian yang digunakan dalam proposal ini adalah penelitian deskriptif dengan menggunakan pendekatan cross seetional yaitu suatu penelitian dimana variabel independen dan variabel dependen diteliti dalam waktu yang sama. ${ }^{9}$ Instrumen yang digunakan dalam pengumpulan data adalah dengan menggunakan kuesioner yang mana data pada pasien pre operasi meliputi poin (a) dukungan keluarga inti, poin (b) dukungan keluarga di luar rumah, poin (c) dukungan keluarga lain. Pertanyaan yang diberikan untuk tingkat kecemasan pasien pre operasi adalah pertanyaan yang berkaitan dengan reaksi emosional pasien pada saat sebelum operasi. Tempat penelitian adalah di Rumah Sakit Umum (RSUD) Andi Makkasau Kota Parepare. Waktu penelitian tanggal 19 Februari 2018 sampai dengan 16 Maret 2018. Adapun yang akan dijadikan populasi dari penelitian ini adalah pasien pre operasi yang ada di Rumah Sakit Umum (RSUD) Andi Makkasau Kota Parepare pada bulan Maret 2018 sebanyak 112 Orang. Pengambilan sampel dalam penelitian ini diambil secara acak sederhana (simple random sampling). 
Jadi, sampel yang diambil adalah sebanyak 53 responden yang merupakan pasien pre operasi yang ada di Rumah Sakit Umum (RSUD) Andi Makkasau Kota Parepare.

Analisis data dalam penelitian ini dengan menggunakan teknik Analisis Univarisat dan Analisis Bivariat.Analisis Univarisat digunakan untuk melihat karakteristik responden yang meliputi dukungan keluarga inti, dukungan keluarga diluar rumah, dukungan keluarga lain dan tingkat kecemasan pasien pre operasi. Penyajian data masing-masing variabel dalam bentuk tabel distribusi prekuensi berdasarkan hasil yang diperoleh. Analisis bivariat digunakan untuk melihat hubungan antara dua variabel yakni variabel dependen dan variabel independen yang diduga berhubungan antara berkorelasi uji hipotesis yang digunakan adalah uji Chi-square.

\section{HASIL PENELITIAN}

Hasil penelitian Tabel 1 menunjukkan karekteristik responden berdasarkan usia, responden terbanyak terdapat pada kelompok usia antara 31 - 40 tahun yaitu sebanyak 22 responden $(41,5 \%)$. Sedangkan kelompok usia paling sedikit yaitu pada kelompok usia antara 41 - 50 tahun sebanyak 12 responden $(22,6 \%)$. Kemudian karekteristik responden berdasarkan jenis kelamin, jumlah pasien pre operasi yang berjenis kelamin laki-laki sebanyak 24 responden (46,3\%). Sedangkan jumlah pasien berjenis kelamin perempuan, sebanyak 29 responden (54,7\%). Karakteristik responden berdasarkan pekerjaan, dimana jumlah pasien pre operasi yang paling banyak yaitu terdapat pada IRT atau ibu rumah tangga dengan jumah 20 responden $(37,7 \%)$, sedangkan jumlah pasien terendah yaitu terdapat pada PNS dengan jumlah pasien sebanyak 14 responden $(26,4 \%)$.

Tabel 2 menunjukkan bahwa dari 53 pasien pre operasi di RSUD Andi Makkasau di Kota Parepare diperoleh data dari pasien pre operasi yang mendapatkan dukungan dari keluarga inti tinggi sebanyak 32 responden $(60,4 \%), 19$ orang $(35,8 \%)$ pasien pre operasi yang memperoleh dukungan pada tingkat sedang, sedangkan pada tingkat rendah terdapat 2 orang $(3,8 \%)$ pasien yang mendapatkan dukungan dari keluarga inti

Tabel 3 menunjukkan bahwa dari 53 responden pasien pre operasi di RSUD Kota parepare, terdapat 23 responden $(43,4 \%)$ yang mendapatkan dukungan yang tinggi dari keluarga diluar rumah, sedangkan pasien pre operasi yang mendapatkan dukungan keluarga diluar rumah pada tingkat sedang terdapat sebanyak 17 responden $(23,1 \%)$ sedangkan pasien pre operasi yang mendapatkan dukungan keluarga di luar rumah pada tingkat terendah terdapat sebanyak 13 responden $(24,5 \%)$.

Tabel 4 menunjukkan bahwa dari 53 responden, berdasarkan dukungan dari keluarga lain. Pasien yang mendapatkan dukungan paling tinggi terdapat sebanyak 22 
responden $(41,5 \%)$, pada kategori sedang terdapat sebanyak 21 responden $(39,6 \%)$, sedangkan pada kategori rendah dukungan yang didapatkan dari keluarga lain terdapat sebanyak 10 responden $(18,9 \%)$.

Tabel 5 menunjukkan bahwa dari 53 responden berdasarkan tingkat kecemasan pasien pre operasi sebagian besar berada pada tingkat kecemasan ringan yaitu terdapat 34 responden $(64,2 \%)$, pada tingkat kecemasan sedang terdapat 13 responden $(24,5 \%)$, sedangkan pada kategori tingkat kecemasan berat terdapat sebanyak 6 responden $(11,3 \%)$.

Pengujian hipotesis dilakukan dengan uji Chi-squeare yang menggunakan taraf signifikansi $(\propto)$ 0,05, dimana untuk kriteria adanya hubungan atau $\mathrm{H}_{0}$ ditolak apabila $\mathrm{p}$ value $<0,05$ dan tidak ada hubungan atau $\mathrm{H}_{0}$ diterima jika $\mathrm{p}$ value $\geq 0,05$. Tabel 6.menunjukkan bahwa dari 53 responden, yang mendapat dukungan kelurga inti cukup tinggi pada tingkat kecemasan ringan sebanyak 32 responden $(60,4 \%)$, responden yang mendapat dukungan keluarga inti sedang dengan tingkat kecemasan ringan sebanyak 2 responden $(3,8 \%)$, responden yang mendapat dukungan keluarga inti sedang dengan tingkat kecemasan sedang sebanyak 13 responden $(24,5 \%)$, sedangkan responden yang mendapat dukungan keluarga inti sedang dengan tingkat kecemasan berat sebanyak 4 responden (7,5\%), dan responden yang mendapat dukungan keluarga inti rendah dengan tingkat kecemasan berat sebanyak 2 responden $(3,8 \%)$.

Berdasarkan hasil analisis yang dilakukan dengan menggunakan Pearson ChiSquare test, dari 53 responden diperoleh nilai $\rho=0,00$ lebih kecil dari nilai $\alpha=0,05$. Dengan demikian Ho ditolak dan Ha diterima, berarti ada hubungan antara dukungan keluarga inti dengan tingkat kecemasan pasien pre operasi di RSUD Andi Makkasau Kota Parepare.

Tabel 7 menunjukkan bahwa dari 53 responden, yang mendapat dukungan kelurga luar rumah tinggi pada tingkat kecemasan ringan sebanyak 23 responden $(43,4 \%)$, untuk responden dengan dukungan keluarga luar rumah sedang pada tingkat kecemasan ringan sebanyak 11 responden (20,8\%), responden dengan dukungan keluarga luar rumah sedang pada tingkat kecemasan sedang sebanyak 6 responden $(11,3 \%)$, sedangkan responden yang mendapat dukungan keluarga luar rumah rendah pada tingkat kecemasan sedang sebanyak 7 responden $(13,2 \%)$, dan responden dengan dukungan keluarga luar rumah rendah pada tingkat kecemasan berat sebanyak 6 responden $(11,3 \%)$.

Berdasarkan hasil analisis yang dilakukan dengan menggunakan Pearson ChiSquare test, dari 53 responden diperoleh nilai $\rho=0,00$ lebih kecil dari nilai $\alpha=0,05$. Dengan demikian Ho ditolak dan Ha diterima, berarti ada hubungan antara dukungan keluarga luar rumah dengan tingkat kecemasan pasien pre 
operasi di RSUD Andi Makkasau Kota Parepare.

Tabel 8 menunjukkan bahwa dari 53 responden, yang mendapat dukungan kelurga lain tinggi pada tingkat kecemasan ringan sebanyak 22 responden (41,5\%), untuk responden dengan dukungan keluarga lain sedang pada tingkat kecemasan ringan sebanyak 12 responden $(22,6 \%)$, dan responden dengan dukungan keluarga lain sedang pada tingkat kecemasan sedang sebanyak 9 responden $(17,0 \%)$, sedangkan responden yang mendapat dukungan keluarga lain rendah pada tingkat kecemasan sedang sebanyak 4 responden $(7,5 \%)$, dan responden dengan dukungan keluarga lain rendah pada tingkat kecemasan berat sebanyak 6 responden $(11,3 \%)$.

Berdasarkan hasil analisis yang dilakukan dengan menggunakan Pearson ChiSquare test, dari 53 responden diperoleh nilai $\rho=0,00$ lebih kecil dari nilai $\alpha=0,05$. Dengan demikian Ho ditolak dan Ha diterima, berarti ada hubungan antara dukungan keluarga lain dengan tingkat kecemasan pasien pre operasi di RSUD Andi Makkasau Kota Parepare.

\section{PEMBAHASAN}

Hubungan antara dukungan keluarga inti dengan tingkat kecemasan pasien pre operasi di RSUD Andi Makkasau Kota Parepare

Hasil penelitian menunjukkan bahwa dari 53 responden, yang mendapat dukungan kelurga inti tinggi pada tingkat kecemasan ringan sebanyak 32 responden $(60,4 \%)$. Sedangkan responden yang mendapat dukungan keluarga inti rendah dengan tingkat kecemasan berat sebanyak 2 responden atau $(3,8 \%)$. Hal ini menunjukkan bahwa semakin tinggi atau semakin banyak dukungan dari keluarga maka tingkat kecemasan pada pasien pun semakin rendah, sebalikanya jika rendah atau kurangnya dukungan atau suport dari keluarga inti maka seorang pasien akan mengalami tingkat kecemasan paling berat. Kesimpulannya dukungan keluarga inti sangatlah memberi pengaruh terhadap mental para pasien pre operasi, semakin banyak yang mendukung maka semakin ringan beban dan tekanan mental yang diderita oleh pasien tersebut.

Berdasarkan hasil analisis yang dilakukan dengan menggunakan Pearson ChiSquare test, dari 53 responden diperoleh nilai $\rho=0,00$ lebih kecil dari nilai $\alpha=0,05$. Dengan demikian Ho ditolak dan Ha diterima, berarti ada hubungan antara dukungan keluarga inti dengan tingkat kecemasan pasien pre operasi di RSUD Andi Makkasau Kota Parepare.

Hasil penelitian ini sejalan dengan penelitia yang dilakukan oleh Rupina Jenita Nadeak (2014) dimana diketahui bahwa ada hubungan antara dukungan keluarga inti dengan tingkat kecemasan pasien pre operasi. $^{10}$

Dukungan keluarga merupakan salah satu faktor yang dapat membantu dalam mengurangi kecemsan pada pasien. Dukungan 
keluarga dapat menimbulkan kenyamanan yaitu dukungan keluarga menahan efek-efek negatif dan stres terhadap kesehatan dan efek utama yaitu dukungan keluarga yang secara langsusng mempengaruhi peningkatan kesehatan, ini menunjukkan adanya fakta hasil penelitian uji univariat bahwa semakin tinggi dukungan keluarga inti seperti orang tua, saudara, suami/istri pada pasien pre operasi maka semakin ringan tingkat kecemasan yang dialami pasien, sehingga lebih mudah sembuh dari sakit, dan ksehatan. Ini diseabkan karna pasien merasa bahwa dukungan dan interaksi dengan dukungan inti seperti orang tu, saudara, suami/istri merupakan kesempatan untuk berbagi pengetahuan, perasaan, informasi sehingga proses operasi dapat berjalan lancar tanpa adanya kecemasan yang berat. ${ }^{11}$

Keluarga inti (orang tua, saudara, suami/istri) merupakan sistem pendukung utama yang memberi perawatan langsusng pada setiap keadaan sehat atau sakit (pasien). Dukungan dari orang tua, saudara, suami/istri adalah hal yang penting, bahkan dapat membantu mempercepat mempercepat proses penyembuhan, tetapi sebaliknya pasien dengan keluarga yang kurang mendukung akan mempersulit proses penyembuhan dan pasien akan cemas berat, Keadaan ini perlu kita sadari sepenuhnya bahwa setiap individu meruakan bagian dari keluarga, juga semua dapat diekspresikan tanpa hambatan yang berarti. $^{12}$
Apabila keluarga menilai bahwa bahaya yang akan dihadapi oleh pasien pre operasi sebagai situasi yang mengancam, menekan bahkan dapat menimbulkan frustasi serta dirasakan melebihi kemampuan pasien untuk melakukan penyesuaian, maka keluarga melakukan upaya untuk menanggulanginya.

Dukungan keluarga tersebut berupa menemani, mencari informasi tentang pembedahan yang akan dilakukan, alasan dilakukan pembedahan, menyiapkan biaya dan mendengarkan keluhannya. Dari uraian tersebut, maka hubungan dukungan keluarga inti dengan tingkat kecemasan pasien pre operasi perlu dipertahankan.

Hubungan dukungan keluarga di luar rumah dengan tingkat kecemasan pasien pre operasi di RSUD Andi Makkasau Kota Parepare

Pada Tabel 7 menunjukkan bahwa dari 53 responden, yang mendapat dukungan kelurga luar rumah tinggi pada tingkat kecemasan ringan sebanyak 23 responden atau $(43,4 \%)$, sedangkan responden dengan dukungan keluarga luar rumah rendah pada tingkat kecemasan berat sebanyak 6 responden (11,3\%). Hal ini di karenakan dukungan keluarga sangat dibutuhkan oleh pasien tidak hanya dukungan dari keluarga inti tetapi juga dukungan dari keluarga luar rumah, hal ini sangatlah memberi pengaruh terhadap mental para pasien pre operasi, semakin banyak yang mendukung maka semakin ringan beban dan 
tekanan mental yang diderita oleh pasien tersebut.

Berdasarkan hasil analisis yang dilakukan dengan menggunakan Pearson ChiSquare test, dari 53 responden diperoleh nilai $\rho=0,00$ lebih kecil dari nilai $\alpha=0,05$. Dengan demikian Ho ditolak dan Ha diterima, berarti ada hubungan antara dukungan keluarga luar rumah dengan tingkat kecemasan pasien pre operasi di RSUD Andi Makkasau Kota Parepare.

Hasil penelitian ini sejalan dengan penelitian yang dilakukan oleh Ariyanto (2014), bahwa ada hubungan antara dukungan keluarga diluar rumah dengan tingkat kecemasan pasien sebelum operasi. ${ }^{13}$

Dukungan dari tante, paman, kemanakan, sepupu, dalam hal memotivasi dan meminimalkan rasa cemas sebelum operasi adalah hal yang sangat penting dalam memenuhi kebutuhan fisik dan emosional pada saat pasien sebelum operasi. Keluarga seperti ini berperan dalam proses pengoatan pasien,sejak awal dirawat sampai dengan sembuhnya pasien, keluarga bertugas memberika kasih sayang dan bantuan sehingga tingkat kecemasan yang ringan yang dialami pasien dan pasien bisa fokus pada kesembuhannya.

Hubungan dukungan keluarga lain dengan tingkat kecemasan pasien pre operasi di RSUD Andi Makkasau Kota Parepare

Pada Tabel 8 menunjukkan bahwa dari 53 responden, yang mendapat dukungan kelurga lain tinggi pada tingkat kecemasan ringan sebanyak 22 responden $(41,5 \%)$, sedangkan responden dengan dukungan keluarga lain rendah pada tingkat kecemasan berat sebanyak 6 responden $(11,3 \%)$. Secara keselurahan dapat disimpulkan bahwa tingginya tingkat dukungan keluarga kepada pasien pre operasi, baik dari keluarga inti, keluarga diluar rumah, maupun keluarga lain sangat dibutuhkan oleh para pasien semakin tinggi atau semakin banyak dukungan yang diberikan pada pasien, maka tingkat kecemasan dalam diri pasien pun semakin ringan.

Berdasarkan hasil analisis yang dilakukan dengan menggunakan Pearson ChiSquare test, dari 53 responden diperoleh nilai $\rho=0,00$ lebih kecil dari nilai $\alpha=0,05$. Dengan demikian Ho ditolak dan Ha diterima, berarti ada hubungan antara dukungan keluarga lain dengan tingkat kecemasan pasien pre operasi di RSUD Andi Makkasau Kota Parepare.

Dukungan keluarga lain tersebut biasanya diinginkan dari orang-orang yang dekat. Selain itu, dukungan keluarga lain seperti sahabat, teman kerja dapat memberikan hiburan, perhatian, penghargaan atau bantuan yang diterima seseorang dari orang lain. Seperti yang telah dikemukakan dihasil penelitian dan uji hipotesis sebelumnya bahwa dukungan dari sahabat, teman kerja, kerabat, rekan kerja, atau juga dari tetangga memiliki hubungan signifikasi dengan tingkat kecemasan pasien pre operasi. Hasil penelitian 
ini sejalan dengan penelitian yang dilakukan

Diana Susilawati (2014), bahwa ada hubungan antara dukungan keluarga lain dengan tingkat kecemasan pasien pre operasi. Ini menunjukkan bahwa dukungan bersumber antara lain: kerabat, pasangan hidup, sahabat, rekan kerja atau juga dari tetangga. ${ }^{14}$

Hal tersebut mengindikasikan seperti sahabat, teman kerja, ataupun tetangga memiliki hubungan yang selalu mendampingi terhada keluarganya yang akan menjalani operasi. Dukungan keluarga lain merupakan suatu bentuk kepedulian sosial. ${ }^{15}$

\section{KESIMPULAN DAN SARAN}

Berdasarkan hasil penelitian diperoleh kesimpulan bahwa ada hubungan yang signifikan antara dukungan keluarga inti ( $\rho=0,00 ; 2)$, dukungan keluarga diluar rumah $(\rho=0,00)$ dan dukungan keluarga lain $(\rho=0,00)$ dengan tingkat kecemasan pasien pre operasi di Rumah Sakit Umum (RSUD) Andi Makkasau Kota Parepare dengan nilai. Berdasarkan hasil penelitian tersebut disarankan kepada keluarga pasien untuk memberikan dukungan dan rasa nyaman kepada pasien sehingga pasien tidak cemas sebelum operasi, bagi tenaga kesehatan untuk lebih ditingkatkan dalam membantu keluarga pasien agar menjalankan fungsinya dalam memberi dukungan agar tingkat kecemasan pasien pre operasi menjadi berkurang, dan disarankan kepada keluarga pasien agar selalu mendampingi pasien dan memberikan motivasi yang baik sehingga pasien tidak cemas sebelum operasi.

\section{DAFTAR PUSTAKA}

1. Friedman. Teori Dukungan Keluarga. Jakarta: EGC; 2012.

2. Stuart dan Sundeen. Prinsip dan Praktik Keperawatan Psikiatrik. Jakarta: EGC; 2013.

3. Smeltzer. Teori Tindakan Operasi. Jakarta: Salembar Medika; 2014.

4. Rothrock. Kecemasan Pasien Pre Operasi. Jakarta: Salembar Medika; 2012.

5. Given. Fungsi Kecemasan. Jakarta: Salembar Medika; 2014.

6. Guendnmann dan Fernsebner. Dukungan Keluarga Secara Informasi dan Pengarahan. Jakarta: Salembar Medika; 2011.

7. Carbonel. Keperawatan Medikal Bedah. Jakarta: Salembar Medika; 2012.

8. Long BC. Kecemasan Pasien Pre Operasi. Jakarta: Salembar Medika; 2012.

9. Notoatmodjo. Metode Kesehatan Masyarakat. Jakarta: Rineka Cipta; 2012.

10. Jenita Nadek.2014. Hubungan Antara Dukungan Keluarga Inti Dengan Tingkat Kecemasan Pasien. Jakarta: Rineka Cipta; 2014.

11. Friedman. Keperawatan Keluarga: Riset, Teori, dan Praktik. Jakarta: EGC; 2014.

12. Suprajino. Dukungan keluarga yang dapat membantu kecemasan pasien. Jakarta: Salembar Medika.; 2013. 
13. Ariyanto. Hubungan Antara Dukungan Keluarga di Luar Rumah Dengan Tingkat Kecemasan Pasien Pre Operasi. Jakarta; 2014.
14. Diana. Hubungan Antara Dukungan Keluarga Lain Dengan Tingkat Kecemasan. Jakarta; 2014.

15. Cohen \&Syme (2012) Dalam Setiadi. Teori Suatu Bentuk Kepedulian. EGC Jakarta; 2013. 


\section{LAMPIRAN}

Tabel 1. Distribusi Responden berdasarkan Usia, Jenis Kelamin, dan Pekerjaan di RSUD Andi Makkasau Kota Parepare

\begin{tabular}{lccc}
\hline & Distribusi Responden & $\mathrm{n}$ & $\%$ \\
\hline Umur (Tahun) & & \\
$20-30$ & 19 & 35,8 \\
$31-40$ & 22 & 41,5 \\
$41-50$ & 12 & 22,6 \\
\hline Jenis Kelamin & & \\
Laki - laki & 24 & 46,3 \\
Perempuan & 29 & 54,7 \\
\hline Pekerjaan & & \\
PNS & 14 & 26,4 \\
Petani & 19 & 35,8 \\
IRT & & 20 & 37,7 \\
\hline & Jumlah & 53 & 100,0 \\
\hline
\end{tabular}

Tabel 2. Distribusi responden berdasarkan dukungan keluarga inti pada pasien pre operasi di RSUD Andi Makkasau Kota Parepare

\begin{tabular}{lccc}
\hline Dukungan Keluarga Inti & $\mathrm{n}$ & $\%$ \\
\hline Tinggi & 32 & 60,4 \\
Sedang & & 19 & 35,8 \\
Rendah & Jumlah & 2 & 3,8 \\
\hline & & 53 & 100,0 \\
\hline
\end{tabular}

Tabel 3. Distribusi responden berdasarkan dukungan keluarga di luar rumah pada pasien pre operasi di RSUD Andi Makkasau Kota Parepare

\begin{tabular}{|c|c|c|}
\hline Dukungan Keluarga diluar Rumah & $\mathrm{n}$ & $\%$ \\
\hline Tinggi & 23 & 43,4 \\
\hline Sedang & 17 & 23,1 \\
\hline Rendah & 13 & 24,5 \\
\hline Jumlah & 53 & 100,0 \\
\hline
\end{tabular}

Tabel 4. Distribusi responden berdasarkan dukungan keluarga lain pada pasien pre operasi di RSUD Andi Makkasau Kota Parepare

\begin{tabular}{lccc}
\hline Dukungan Keluarga lain & $\mathrm{n}$ & $\%$ \\
\hline Tinggi & 22 & 41,5 \\
Sedang & 21 & 39,6 \\
Rendah & 10 & 18,9 \\
\hline & Jumlah & 53 & 100,0 \\
\hline
\end{tabular}


Tabel 5. Distribusi responden berdasarkan tingkat kecemasan pada pasien pre operasi di RSUD Andi Makkasau Kota Parepare

\begin{tabular}{lccc}
\hline Tingkat Kecemasan & $\mathrm{n}$ & $\%$ \\
\hline Kecemasan ringan & 34 & 64,2 \\
Kecemasan sedang & 13 & 24,5 \\
Kecemasan berat & Jumlah & 6 & 11,3 \\
\hline & & 53 & 100,0 \\
\hline
\end{tabular}

Tabel 6. Hubungan dukungan keluarga inti dengan tingkat kecemasan pasien pre operasi di RSUD Andi Makkasau Kota Parepare

\begin{tabular}{|c|c|c|c|c|c|c|c|c|c|}
\hline \multirow{3}{*}{$\begin{array}{c}\text { Dukungan } \\
\text { Keluarga Inti }\end{array}$} & \multicolumn{6}{|c|}{ Tingkat Kecemasan } & \multirow{2}{*}{\multicolumn{2}{|c|}{ Total }} & \multirow{3}{*}{$\rho$} \\
\hline & \multicolumn{2}{|c|}{$\begin{array}{c}\text { Kecemasan } \\
\text { Ringan }\end{array}$} & \multicolumn{2}{|c|}{$\begin{array}{c}\text { Kecemasan } \\
\text { Sedang }\end{array}$} & \multicolumn{2}{|c|}{$\begin{array}{c}\text { Kecemasan } \\
\text { Berat }\end{array}$} & & & \\
\hline & $\mathrm{n}$ & $\%$ & $\mathrm{n}$ & $\%$ & $\mathrm{n}$ & $\%$ & $\mathrm{n}$ & $\%$ & \\
\hline Tinggi & 32 & 60,4 & 0 & 0,0 & 0 & 0,0 & 32 & 60,4 & \multirow{4}{*}{0,00} \\
\hline Sedang & 2 & 3,8 & 13 & 24,5 & 4 & 7,5 & 19 & 35,8 & \\
\hline Rendah & 0 & 0,0 & 0 & 0,0 & 2 & 3,8 & 2 & 3,8 & \\
\hline Total & 34 & 64,2 & 13 & 24,5 & 6 & 11,3 & 53 & 100,0 & \\
\hline
\end{tabular}

Tabel 7. Hubungan dukungan keluarga di luar rumah pada pasien pre operasi di RSUD Andi Makkasau Kota Parepare

\begin{tabular}{|c|c|c|c|c|c|c|c|c|c|}
\hline \multirow{3}{*}{$\begin{array}{l}\text { Dukungan Keluarga } \\
\text { Diluar Rumah }\end{array}$} & \multicolumn{6}{|c|}{ Tingkat Kecemasan } & & & \multirow{3}{*}{$\rho$} \\
\hline & \multicolumn{2}{|c|}{$\begin{array}{c}\text { Kecemasan } \\
\text { Ringan }\end{array}$} & \multicolumn{2}{|c|}{$\begin{array}{c}\text { Kecemasan } \\
\text { Sedang } \\
\end{array}$} & \multicolumn{2}{|c|}{$\begin{array}{c}\text { Kecemasan } \\
\text { Berat } \\
\end{array}$} & \multicolumn{2}{|c|}{ Total } & \\
\hline & $\mathrm{n}$ & $\%$ & $\mathrm{n}$ & $\%$ & $\mathrm{n}$ & $\%$ & $\mathrm{n}$ & $\%$ & \\
\hline Tinggi & 23 & 43,4 & 0 & 0,0 & 0 & 0,0 & 23 & 43,4 & \multirow{4}{*}{0,00} \\
\hline Sedang & 11 & 20,8 & 6 & 11,3 & 0 & 0,0 & 17 & 32,1 & \\
\hline Rendah & 0 & 0,0 & 7 & 13,2 & 6 & 11,3 & 13 & 24,5 & \\
\hline Total & 34 & 64,2 & 13 & 24,5 & 6 & 11,3 & 53 & 100,0 & \\
\hline
\end{tabular}

Tabel 8. Hubungan dukungan keluarga lain pada pasien preoperasi di RSUD Andi Makkasau Kota

\begin{tabular}{|c|c|c|c|c|c|c|c|c|c|}
\hline \multirow{4}{*}{ Dukungan Keluarga lain } & \multicolumn{6}{|c|}{ Parepare } & & & \\
\hline & \multicolumn{6}{|c|}{ Tingkat Kecemasan } & & & \multirow{3}{*}{$\rho$} \\
\hline & \multicolumn{2}{|c|}{$\begin{array}{l}\text { Kecemasan } \\
\text { Ringan }\end{array}$} & \multicolumn{2}{|c|}{$\begin{array}{l}\text { Kecemasan } \\
\text { Sedang }\end{array}$} & \multicolumn{2}{|c|}{$\begin{array}{c}\text { Kecemasan } \\
\text { Berat }\end{array}$} & \multicolumn{2}{|c|}{ Total } & \\
\hline & $\mathrm{n}$ & $\%$ & $\mathrm{n}$ & $\%$ & $\mathrm{n}$ & $\%$ & $\mathrm{n}$ & $\%$ & \\
\hline Tinggi & 22 & 41,5 & 0 & 0,0 & 0 & 0,0 & 22 & 41,5 & \multirow{4}{*}{0,00} \\
\hline Sedang & 12 & 22,6 & 9 & 17,0 & 0 & 0,0 & 21 & 39,6 & \\
\hline Rendah & 0 & 0,0 & 4 & 7,5 & 6 & 11,3 & 10 & 18,9 & \\
\hline Total & 34 & 64,1 & 13 & 24.5 & 6 & 113 & 53 & 100,0 & \\
\hline
\end{tabular}

